\title{
Patient's evaluation of dietetic care: testing a cognitive-attitude approach
}

\author{
Jan J. Kerssens ${ }^{\mathrm{a} . *}$, Ellen M. van Yperen ${ }^{\mathrm{b}}$ \\ ${ }^{a}$ Research Associate, Consumers Department, Netherlands Institute of Primary Health Care. Utrecht, The Netherlands \\ "Operational Manager Food and Diet Education. Foundation 'Home Care Drenthe', Assen. The Netherlands
}

Received 31 July 1994; revision received 25 April 1995: accepted 15 May 1995

\begin{abstract}
The study of patients' attitudes is an important subject because the success of many medical programs is linked to it. We have used a cognitive attitude theory - the Elaboration Likelihood Model (ELM), to study how patients form an evaluation of dietetic care. Respondents answered one questionnaire before (46\% response) and one questionnaire after $(60 \%$ response) their first consultation with a primary care dietitian. Patients rated their pre-test quality expectations and post-test quality evaluations of each of 28 distinctive aspects of care. They also rated the relative importance of each aspect. According to the ELM, people of high motivation and capacity to process information do so in an elaborate way. From this model five hypotheses are derived. Patients who elaborate are assumed to show a more differentiated pattern in (1) their quality expectations, (2) their rating of importance and (3) their quality judgements of distinctive aspects of dietetic care than people who do not elaborate. Furthermore, they are expected to show (4) a weaker association between quality expectation and quality judgement, and (5) relatively more extreme quality judgements. The three first hypotheses are accepted, the evidence of the last two is still inconclusive.
\end{abstract}

Keywords: Quality of care; Consumer satisfaction; Client attitudes; Dietetics

\section{Introduction}

\subsection{Patients' evaluation}

The success of many preventive care programs and ambulatory care treatment depends upon a

* Corresponding author, Nivel, P.O. Box 1568, 3500 BN Utrecht, The Netherlands. Tel.: (+31-30) 319 946; Fax: $(+31-$ 30) 319290 . positive attitude in the target populations. But only little is known about patient's evaluations of health care and almost nothing about the psychological processes on which evaluations are based. The current disconfirmation paradigm postulates that patient evaluation (and patient satisfaction) results from a comparison of patient's expectations and patient's perception of provider's performance [1]. This paradigm is used in different fields, like in the evaluation of commercial prod- 
ucts [2], patient satisfaction [3-4] and in the appreciation of business services [5-6]. But disconfirmation alone does not offer knowledge about the psychological process that leads to satisfaction. More sophisticated attitude theories are needed. One of these theories, the Elaborating Likelihood Model (ELM) developed by Petty and Cacioppo [7] seems to be particularly suitable for medical professions that rely on patient education. According to the ELM people process information either actively and carefully or superficially and without much thought or elaboration. Individuals will consider the pros and cons of the health care experience more or less thoroughly, depending on their motivation and capacity for information processing. So motivation and capacity are prominent concepts in ELM, just as in patient education, where motivation determines compliance [8] and capacity forms a condition for the information that can be absorbed [9].

Our study translates the ELM to fit the concept of patient satisfaction. Although the study's object is quite general, it is in the domain of primary dietetic care. Research on patient satisfaction in the field of allied health professions is still rather scarce. A recent literature search on methods for assessing patient satisfaction with primary care revealed only a few references related to fields other than medicine. There was no reference on satisfaction with dietetics [10]. To our knowledge, this study is the first to address the following questions:

1. What are the patient's evaluations of different aspects of the quality of dietetic care and what do patients perceive to be the key attributes of quality in dietetic care?

2. How does the way the information is processed (elaborate or not) affect the evaluation of the different aspects of the quality of dietetic care?

Before the implications of the ELM are hypothesized, a short explanation of the disconfirmation paradigm is presented.

\subsection{Disconfirmation paradigm}

According to Betmann [11] many studies support the model of consumer satisfaction as a function of both performance, expectation and degree of disconfirmation. The underlying assumption of this model is quite simple: if a product matches its expectations then quality is satisfactory. Satisfaction thus emanates from confirmed expectations. If a product however fails to match its expectations then quality will be judged as unsatisfactory. And if a product excels its expectation, quality will be judged as very satisfactory or even excellent. In other words: dissatisfaction results from disconfirmation [12]. This model has been connected to different attitude theories. For instance Helson's adaptation level theory of judging stimuli [13] and Sherif and Hovland's assimilation-contrast theory [14]. Anderson [15] compared five competing attitude theories in the domain of consumer satisfaction and observed that the assimilation-contrast model fitted his data best.

In the assimilation-contrast model expectation serves as a standard for judging a service but not every discrepancy will result in disconfirmation; there is a certain zone surrounding the standard (this zone is named the 'latitude of acceptance' [16], for our purpose 'assimilation zone' seems more appropriate). Fig. 1 depicts this situation. A perception within the zone is assimilated, which means that it is shifted towards its expectation.

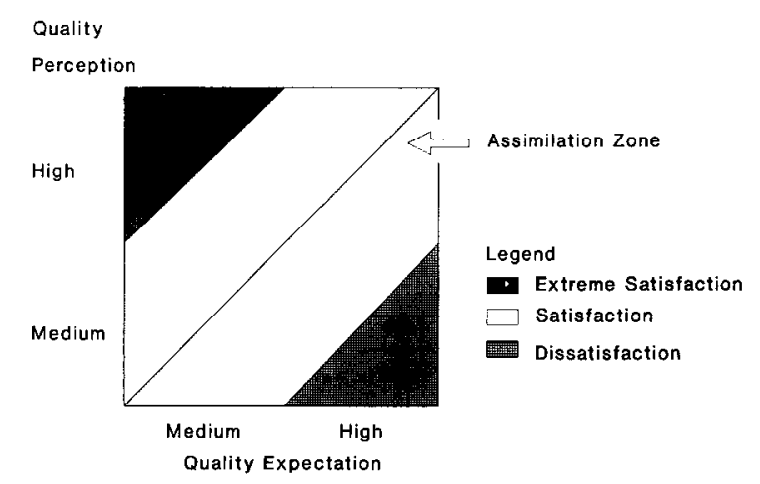

Fig. 1. The relation between expectation and perception according to the assimilation-contrast theory in the domain of patient satisfaction. 
Perception and expectation are integrated because of assimilation. A health care experience, perceived to fall on the diagonal or within the assimilation zone, is confirmed and leads to a sense of satisfaction. But a perception outside the zone is contrasted, that is, shifted away from its expectation. Perception and expectation become more incongruent because of contrast. A health care experience outside the assimilation zone is disconfirmed and leads to dissatisfaction [17-19]. Or to extreme satisfaction when perception exceeds expectation (see Fig. 2 for a graphical explanation). Pascoe discusses the assimilation-contrast approach in patient satisfaction research and noticed that given some ambiguity for patients about aspects of health care services, the assimilation zone is rather broad. Satisfaction is therefore fairly common [3].

The Elahoration I ikelihood Model formulates an explanation of the assimilation-contrast phenomenon. According to this model there are different paths to process information. These paths are called the central and the peripheral route:

- The central route involves diligent consideration of information, that is, a person is actively and carefully thinking about the true merits of the health care experience;

- The peripheral route includes any kind of superficial evaluation that occurs without much thought or elaboration. A person does not consider the pros and cons of the health care experience but makes a simple evaluation based on simple cues.

With sufficient motivation and capacity to process the information by central route, people will respond to the different attributes of the quality of health care. Individuals who process information by central route will find the health care experience less ambiguous than others. As a consequence they will have relatively smaller assimilation zones. Without motivation and capacity, however, information will be processed by peripheral route and the different attributes will not receive much thought. These individuals will have relatively larger assimilation zones.

The ELM gives thus rise to a distinction between individuals, from which the following five hypotheses are derived. Patients who process information by the central route:

1. Show more differentiation among their expectations of distinctive aspects in the quality of care;

2. Show more differentiation when rating the importance of distinctive aspects in the quality of care;

3. Show more differentiation among their quality judgements of distinctive aspects of care;

4. Show a weaker association between quality judgement and quality expectation;

5. Show relatively more extreme quality judgements;

than patients who process information by the peripheral route.

The first three hypotheses are related to the elaboration of information. They all follow from the assumption that patients who give their health care experience a great deal of thought are much more able to discern what is actually happening and are more aware of their own attitudes than people who do not consider all the pros and cons of their consultation with the dietitian. Elaborating the information will thus lead to a more differentiated pattern of distinctive expectations, ratings of importance and quality judgements.

The last two hypotheses have to do with assimilation and contrast. The fourth hypothesis originates from the assumption that peripheral route patients have larger assimilation zones and the probability that their perception is shifted towards their expcctation is therefore higher. The fifth hypothesis is born from the contrast side of the medal: central route patients have smaller assimilation zones, will, as a consequence, show more contrast and therefore experience more disconfirmation of expectation. Hence, they will show more extreme quality judgements, either negative or positive. 


\section{Methods}

\subsection{Design}

The study design is pre-test/post-test with control group [20]. Only half of the patients who were to receive the post-test received the pre-test (response $46 \%$ numbering 115 patients). The other half formed a control group in order to determine pre-test effects on post-test scores. The post-test was answered by 333 patients $(60 \%$ response). Since no effect was observed, the two groups were not distinguished any further.

\subsection{Sample}

In the Netherlands approximately $15 \%$ of the dietitians work in primary care [21]. This study is restricted to their services. Patients consult these dietitians on referral by physicians. In our case $81 \%$ of the patients are referred by general practitioners, $7 \%$ by internists and $6 \%$ by cardiologists. The patients are especially advised about low-energy diets $(74 \%)$, diets with multiple unsaturated fatty acids for low cholesterol $(34 \%)$, diets for diabetics $(16 \%)$, low-sodium diets $(15 \%)$ or diets for food intolerance or food allergy $(7 \%)$. Often a combination advice is offered. The mean age of the patients is 48 years (S.D. 19), 67\% are female. The information is gathered by 10 dietitian's at 32 different locations in the province of Drenthe, the Netherlands.

\subsection{Procedure}

The questionnaires were filled in before and after the first consultation with a primary care dietitian in February 1991. The quality of dietetic care was assessed on 28 items concerning various aspects (see Table 1 for short descriptions). Patients rated their pre-test expected quality of each attribute. For instance: How well do you expect to understand the information? With categories: excellent, very well, well, reasonably, badly, no opinion. The response format with more categories on the positive side of the item scale is advocated by Rubin et al. [22]. Each item forms a part of the overall quality expectation.
Item scores were scaled in order to obtain an overall quality expectation (Reliability analysis was performed by means of a multi-level procedure [23], Cronbach's $\alpha$ is 0.97).

In the post-test the same list of items came back twice. First, the patients rated the relative importance of each attribute. For instance: How important is it for you to understand the information? With categories: of great importance, of importance, of little importance, of no importance, no opinion. Secondly, the patients evaluated the quality of each attribute. For instance: How do you evaluate the intelligibility of the information? With the same categories that followed the expectations. Also the same procedure as with overall expectation was followed for an overall quality judgement (Cronbach's $\alpha$ is 0.94).

Motivation and capacity are two important variables in determining whether patients process information by the central or peripheral route. In the post-test patients answered questions about motivation and capacity. Motivation is considered high if patients reported to judge their health problem as very serious and answered that they themselves felt responsible for their health. Capacity is high if patients indicated that they had already read or heard a lot about their health problem, had received neither too little nor too much information, were able to pay attention and were not distracted during their consult (all these in combination with one other). Patients were divided on this bases into three groups. Patients of high capacity and of high motivation $(N=95)$ who were assumed to process information by central route. Patients of low capacity and of low motivation $(N=85)$ who were assumed to use the peripheral route. The data on the patients in between (low on motivation and high on capacity or vice versa, $N=163$ ) were disregarded in order to heighten the contrast.

\subsection{Data analysis}

The first hypothesis is tested with pre-test scores on the level of attributes. The second and third are tested with post-test scores on the same level. The hypotheses are tested in a multilevel 
analysis [24] by means of which one can impose variance components within patients as well as between patients [25]. 'The within variance of central route patients is compared to the within variance of peripheral route patients. Furthermore, a statistical test for the null hypothesis for equal variances was obtained by comparing the values of the loglikelihood function. The scaled deviance (D) indicates the test statistic [26]. The fourth hypothesis is tested with pre- and post-test overall scores of both expectations and quality judgements by means of comparing correlations for central route and peripheral route patients. To test whether or not the correlations differ statistically, the linear regression $F$-test of the 'expectation $\times$ processing route' interaction term was calculated [27]. The fifth and last hypothesis is tested by means of $\chi^{2}$ analyses on post-test overall quality judgements. Hypotheses four and five are analyzed on the patient level. The testing of hypotheses relates to the second research question. The first research question is answered quite straightforwardly by means of post-test scores for each item and for all patients.

\section{Results}

Table 1 neatly summarizes the results with respect to the first research question. The ranks are formed on basis of the percentage of patients who rated the distinctive attributes of great importance'. The most important aspect of the quality of care, according to the patients, is the dietitian's expertise, rated by $72 \%$ of great importance. Somewhere in the middle (rank 14) the feasibility of advice is found. rated by $50 \%$ of the patients as of great importance. The lcast important attribute is the way appointments are made, rated by only $32 \%$ of the patients in the category of great importance. Table 1 also presents the quality judgement of each distinctive attribute. Being taken seriously received the highest quality score; $59 \%$ percent of the patients evaluated this attribute as 'excellent' or 'very good'. A middle position is taken by the emotional support that patient experienced from their dietitian: $45 \%$ excellent or very good. The
Table 1

Ranking of attributes by importance (most left column) and quality judgements of dietetic care (percentages of patients who responded in categories: excellent and very good, $N=$ 333)

\begin{tabular}{rll}
\hline Rank & Attribute & $\begin{array}{l}\text { Quality } \\
\text { judgement }\end{array}$ \\
\hline 1. & Dietitian's expertise & $55.3 \%$ \\
2. & Being taken seriously & $59.0 \%$ \\
3. & Confidentiality of information & $37.0 \%$ \\
4. & Sensitive to problems & $45.6 \%$ \\
5. & Problem clarification & $49.7 \%$ \\
6. & Usefulness of information & $46.2 \%$ \\
7. & Dietitian's effort & $57.0 \%$ \\
8. & Pertaining of advise & $43.3 \%$ \\
9. & Explicit about treatment & $46.5 \%$ \\
10. & Intelligibility of information & $45.6 \%$ \\
11. & To feel comfortable & $57.0 \%$ \\
12. & Availability & $28.7 \%$ \\
13. & Dietitian's support & $44.6 \%$ \\
14. & Feasibility of advice & $34.9 \%$ \\
15. & Length of consultation & $55.2 \%$ \\
16. & Consideration of feelings & $41.7 \%$ \\
17. & Consideration of situation & $43.6 \%$ \\
18. & Emotional interest & $34.8 \%$ \\
19. & Match of problem and treatment & $37.3 \%$ \\
20. & Conversation technique & $55.3 \%$ \\
21. & Amount of information & $48.1 \%$ \\
22. & Openness about referral & $28.6 \%$ \\
23. & Helped on time & $43.9 \%$ \\
24. & Cooperation with physician & $23.5 \%$ \\
25. & Accessibility & $\mathbf{3 3 . 1} \%$ \\
26. & Number of follow up visits & $28.2 \%$ \\
27. & Time to make a decision & $29.6 \%$ \\
28. & The way appointments are made & $36.1 \%$ \\
\hline
\end{tabular}

lowest score was given to the way the dietitian cooperates with the referring physician: only $24 \%$ excellent or very good. A complete comment on Table 1 is given by Yperen and Kerssens [28].

The results on the first, sccond and third hypotheses are presented in Table 2 . The lefthand side of the table shows that the mean expectations of the central route patients is somewhat higher than that of the peripheral route patients. The testing however concerns the ratio of the within patients variance of the central and the peripheral route. This ratio $(0.48 /$ $0.32=1.5, P<0.01)$ clearly indicates that central route patients show more variance (differentiation) among their expectations than peripheral 
Table 2

Regression coefficients, associated standard errors (in parentheses) and equal variance test statistics for three multilevel item response models

\begin{tabular}{|c|c|c|c|c|c|c|}
\hline \multirow[t]{3}{*}{ Explanatory variables } & \multicolumn{6}{|c|}{ Response variables } \\
\hline & \multicolumn{2}{|l|}{ Expectation } & \multicolumn{2}{|c|}{ Importance Rating } & \multicolumn{2}{|c|}{ Quality judgement } \\
\hline & Coefficient & $\begin{array}{l}\text { Standard } \\
\text { error }\end{array}$ & Coefficient & $\begin{array}{l}\text { Standard } \\
\text { error }\end{array}$ & Coefficient & $\begin{array}{l}\text { Standard } \\
\text { error }\end{array}$ \\
\hline \multicolumn{7}{|l|}{ Mean } \\
\hline Central & 4.39 & $(0.188)$ & 4.49 & $(0.045)$ & 4.67 & $(0.090)$ \\
\hline Peripheral & 4.16 & $(0.207)$ & 4.45 & $(0.047)$ & 4.58 & $(0.094)$ \\
\hline \multicolumn{7}{|l|}{ Variance } \\
\hline Between patients & 0.40 & $(0.074)$ & 0.11 & $(0.009)$ & 0.46 & $(0.037)$ \\
\hline \multicolumn{7}{|l|}{ Pooled within patients } \\
\hline Central & 0.48 & $(0.030)$ & 0.21 & $(0.006)$ & 0.44 & $(0.013)$ \\
\hline Peripheral & 0.32 & $(0.022)$ & 0.15 & $(0.005)$ & 0.36 & $(0.012)$ \\
\hline Test Statistic $D$ & $54.14^{*}$ & & $137.20^{*}$ & & $41.00^{*}$ & \\
\hline
\end{tabular}

Expectation on the left-hand side, rating of importance in the middle and quality judgement on the right-hand side. $D$ has approximately a $\chi^{2}$ distribution with 1 degree of freedom.

$* P<0.01$.

route patients. The first hypothesis is therefore accepted.

In the middle of the table, the results regarding the rating of importance are presented. The mean importance rating is roughly the same for the central and peripheral routes. But the within variance of the patients who process information by central routc is certainly larger compared to the variance of the peripheral route $(0.21 / 0.15=$ $1.4, P<0.01)$. This is also consistent with the theoretical anticipation and so the second hypothesis is accepted: patients who process information by central route show more differentiation when rating the importance of distinctive attributes than patients who process information by peripheral route.

The right hand side of the table gives the results concerning the third hypothesis. The mean quality judgement is somewhat higher in the central route. And again, the central route patients show more variance than the peripheral route patients, the ratio is $0.44 / 0.36=1.2(P<$ $0.01)$. So patients who process information by the central route differentiate more among the quality judgements of distinctive attributes than patients who process information by peripheral route.

Fig. 3 shows scatterdiagrams and linear trends of pre-test expectations and post-test quality judgements for two types of information processing; central route patients on the left panel, peripheral route patients on the right. The correlation analysis further revealed that the relation between quality judgement and expectation is less strong for patients who processed the information by central route $(r=0.37)$ than for peripheral route patients $(r=0.75)$. This result points to more assimilation at face value, but the appropriate test statistic $\left(F_{(1,44)}=3.35\right)$ just fails to reach statistical significance $(0.10>P>0.05)$. The fourth hypothesis is therefore rejected. There is just a bit too little evidence in the data to conclude that patients who process information by the central route have a weaker association between expectation and judgement than patients who process information by the peripheral route.

The fifth and last hypothesis is about extreme quality judgements. The test results, presented in Table 3, are not completely in line with the assumption. Although there are slightly more quality judgements at the positive extreme in the central route patients, negative extremes are virtually absent. The $\chi^{2}$ test indicates no statistically significant differences between the two groups $(0.10>p>0.05)$. The fifth hypothesis is 


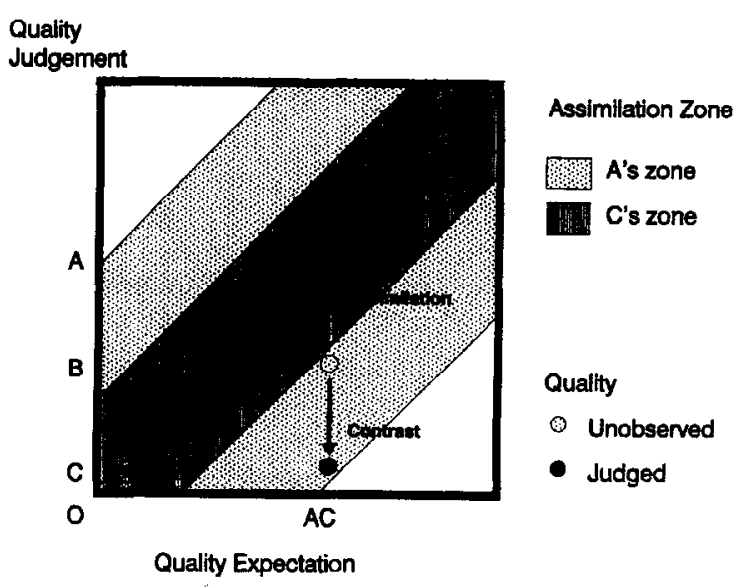

Fig. 2. A graphical explanation of assimilation and contrast: assimilation and contrast as a function of assimilation zone. The figure forms a space for every possible pair of quality expectation and quality judgement. Two such pairs are indicated by the black circles. Consider a situation of two individuals $\mathrm{A}, \mathrm{C}$ who had exactly the same quality expectations (line $\mathrm{O}-\mathrm{AC}$ ) and who has both been receiving health care of identical quality (line $\mathrm{O}-\mathrm{B}$ ) that fell short of their expectation (the open circle). The individuals diverge only in the size of their assimilation zone. Individual A's zone encompasses the actually received quality. So there is an upward shift called assimilation that results in a quality judgement more positive than the quality received $(\mathrm{O}-\mathrm{A}>$ $\mathrm{O}-\mathrm{B})$. Because of assimilation $\mathrm{A}$ 's quality judgement becomes congruent with his expectation $(\mathrm{O}-\mathrm{A}=\mathrm{O}-\mathrm{AC})$. C's assimilation zone, on the contrary, does not include the actually received quality. So there is an downward shift called contrast causing a quality judgement less positive than the quality received $(\mathrm{O}-\mathrm{C}<\mathrm{O}-\mathrm{B})$. Because of contrast $\mathrm{C}$ 's quality judgement becomes more incongruent with his expectation $(\mathrm{O}-\mathrm{C} \neq \mathrm{O}-\mathrm{AC})$.
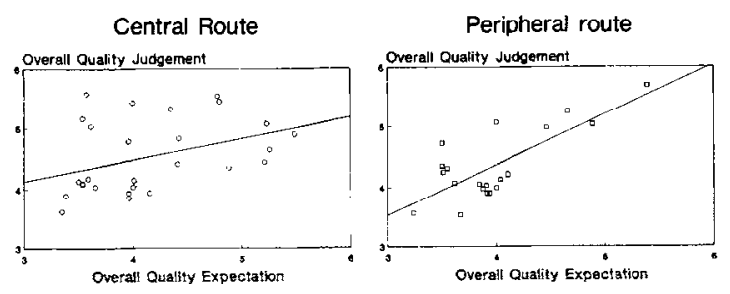

Fig. 3. The relation between pre-test expectation and posttest quality judgement of dietetic care by information processing route.

therefore also rejected. Patients who process information by the central route do not show relatively more extreme quality judgements than patients who process information by the peripheral route.

\section{Discussion}

Patient satisfaction measurement matters for more reasons than building theories of how people form opinions. A well-designed, implemented, and utilized patient satisfaction measurement system can help health care managers improve their clinical and administrative activities [29]. For instance, our results point to discrepancy between the rating of importance and the quality judgements of some attributes. The aspect of confidentiality was rated as very important but qualified as only reasonable. Without much extra effort, however, dietitians can give patients more insight in ethical procedures such as the oath of secrecy, laws of privacy, the way in which patient status is handled, and the content of the report to the referring physician. Another discrepancy is found in the waiting time for primary care dietetics. When we were conducting our research, there was a maximum waiting period for 4 weeks. The patient's evaluation of availability clearly indicates the need for administrative activities to reduce the waiting list.

This pragmatic approach to patient satisfaction, adopted by the large majority of health care researchers, raises the question of whether patient satisfaction can serve as an indicator of quality care [30]. There is evidence that patients can validly evaluate the quality of health care. Rubin [31] reports three studies where patients evaluations of hospital care have changed with experimental interventions aimed at improving the quality of care [32-34]. Furthermore, Carlberg and Tibblin [35-36] showed that a group of hypertensives who received a non-pharmacological treatment were more satisfied than a control group receiving traditional treatment, because of improvements in factors like doctor-continuity, patient-doctor relation and patient participation. The fact that patient satisfaction does increase if aspects of care (believed to determine satisfac- 
Table 3

Frequencies and percentages of patients on overall quality judgement of dietetic care by information processing route $(N=177)^{*}$

\begin{tabular}{llllll}
\hline Overall judgement & \multicolumn{2}{l}{ Central route } & & \multicolumn{2}{l}{ Peripheral route } \\
\cline { 2 - 3 } \cline { 5 - 6 } & Number & $\%$ & & Number & $\%$ \\
\hline Excellent & 15 & $15.8 \%$ & 9 & $11.0 \%$ \\
Very good & 35 & $36.7 \%$ & 29 & $35.4 \%$ \\
Good & 45 & $47.4 \%$ & & 42 & $51.2 \%$ \\
Fair & 2 & $2.1 \%$ & 2 & $2.4 \%$ \\
Column total & 95 & $100.0 \%$ & 82 & $100.0 \%$ \\
\hline
\end{tabular}

$\chi^{2}=3.23$ with three degrees of freedom, $P>0.05$.

* Three missing values.

tion) improve, is a strong argument in favour of the use of patient satisfaction measurements [37].

Nearly all patient satisfaction reviews, the older ones [38-39], as well as the more recent ones [40-41], call for more consideration of conceptual and theoretical problems in patient satisfaction. Our study is concerned with these issues. The acceptation of hypotheses 1,2 and 3 , demonstrated the validity of the Elaboration Likelihood Model in the realm of satisfaction with dietetics. Patients who are motivated and capable to elaborate all the information do indeed so, in contrast to those who are not motivated and capable. Both motivation and capacity are operationalized, not as personality traits, but in a specific time and situation context. Capacity, for instance, is high if patients received not too little nor too much information and were able to concentrate their attention at the consultation. These are clearly circumstances under control of the dietitian. The conclusion is justified that the process by means of which patients decide whether the dietetic care is to their satisfaction or not is subject to individual differences of information processing.

The Elaboration Likclihood Model itself withstands the empirical tests but the evidence on its connection to assimilation and contrast proved not to be completely convincing. Although we have found some indications that people who do not elaborate the information show more assimilation (hypothesis 4) and people who do elaborate show more contrast (hypothesis 5), both statistical tests just failed to reach significance at $\alpha 0.05$. Although there is slightly more quality judgements at the positive extreme in the central route patients, negative extremes are nearly absent. The level of overall quality judgement is rather high, for both groups of patients. We are tempted to conclude that the overall quality of primary dietetic care itself gives rise to these positive evaluations, irrespective of the way in which patients have processed the information. We have explored this line of reasoning as follows: not each and every single quality attribute is rated as high as the overall quality. Waiting time, for instance, was evaluated less positively than overall quality, so the probability of disconfirmation of expected waiting time must be higher. Furthermore, highly motivated patients will be more eager to start treatment and will be consequently more frustrated by waiting times. Cross tabulation quality judgement on waiting time by motivation confirms this line of reasoning. High motivated patients do indeed judge waiting time less satisfactory compared to low motivated patients $\left(\chi^{2}=7.84, d f=3, P<\right.$ 0.05 ) but real disconfirmation and negative evaluations are still absent. It is generally acknowledged that we should expect high levels of satisfaction [42]. Our figures demonstrates the appropriateness of this statement again. The figures (like all figures from patient satisfaction research) are not to be considered in an absolute sense. They are only useful in a comparative sense.

The magnitude of the assimilation zone can not be explained entirely by the way information is processed. Still assimilation remains an appealing concept. It offers an elegant reason for omnipresent high satisfaction scores and the strong bond between expectation and evaluation. 
Linder-Pelz [43-44] based her definition of patient satisfaction on the attitude theory of Fishbein and Ajzen [45] but could not demonstrate the validity of her approach. One of the findings of her empirical testing was that expectations and satisfaction are closely related. Positive expectation and high satisfaction went together. The same issue was raised by Fitzpatrick and Hopkins [46], which offered the following explanation: since expectations are revised in the light of experience, both expectations and satisfaction are almost identical evaluations of health care. Our (inconclusive) evidence of assimilation (hypothesis 4) shows however that this does not apply to all patients. Furthermore, it seems that only in health care services of an invariable quality level identity of expectation and evaluation can be anticipated. But health services of invariable quality do not exist.

Strasser et al. [47] have developed a comprehensive model of the patient satisfaction process by formulating six principles. One of those, the principle of individual differences is addressed in our study. The theoretical assumption that people of high motivation and of high capacity process information elaborately is confirmed. The theoretical assumption that patients who do elaborate, base their evaluation on the quality of the delivered service, while patients who do not elaborate are guided by their expectation also, is still inconclusive and needs more evidence.

\section{References}

[1] Ross CK, Frommelt G, Ilazelwood L, Chang RW. The role of expectation in patient satisfaction with medical care. J Health Care Marketing 1987; 7: 16-26.

[2] Oliver RL. A cognitive model of antecedents and consequences of satisfaction decisions. J Marketing 1980; 17: $460-469$.

[3] Pascoe GC. Patient satisfaction in primary health care: a literature review and analysis. Eval Progr Plan 1983; 6 ; $185-210$.

[4] Babakus E, Mangold WG. Adapting the SERVQUAL scale to hospital services: an empirical investigation. Health Serv Res 1992: 26: 767-786.

[5] Parasuraman A, Zeithalm VA, Berry LL. A conceptual model of service quality and its implications for future research. J Marketing 1985; 49 (Fall): 41-50.

[6] Parasuraman A, Zeithalm VA. Berry LL. SERVQUAL: a multiple-item scale for measuring consumer perceptions of service quality. J Retailing $1988 ; 64: 12-40$.

[7] Petty RE, Capiocco T. Communication and persuasion: central and peripheral routes to attitude change. New York: Springer Verlag, 1986.

[8] Ley P. Satisfaction, compliance and education. Br J Clin Psychol 1982; 21: 241-254.

[9] DiMatteo MR, Prince LM, Taranta A. Patients' perceptions of physicians' behavior: determinants of patient commitment to the therapeutic relationship. J Community Health 1979; 4: $280-290$.

[10| Campen C van, Friele RD, Kerssens JJ. Methods for assessing patient satisfaction with primary care. Utrecht: Netherlands Institute of Primary Health Care, 1992.

[11] Bettman JR. Consumer psychology. Annu Rev Psychol 1986; 2: 275-289.

[12] O'Conner S.I, Bowers MR. An integrative overview of the quality dimensions: marketing implications for the consumer-oriented health care organization. Med Care Rev 1990; 47: 193-219.

[13] Helson H. Adaptation-level theory. New York: Harper \& Row, 1964

[14] Sheriff M, Hovland CI. Social judgements: assimilation and contrast effects in communication and attitude change. New Haven, CT: Yale University Press, 1961.

[15] Anderson RE. Consumer dissatisfaction: the effect of disconfirmed expectancy on perceived product performance. J Marketing Res 1973; 10: 38-44.

[16] Sherif M, Sherif CW. Attitude as the individual's own categories: the social judgement-involvement approach to attitude and attitude change. In: Sherif $\mathrm{CW}$, Sherif $\mathrm{M}$ editors. Attitude, ego-involvement and change. New York: John Wiley \& Sons. 1967; 105-137.

[17] Olshavsky RW, Miller JA. Consumers expectations, product performance and perceived product quality. $J$ Marketing Res 1972: 9: 19-21.

[18] Olsen JC, Dover P. Effects of expectations, product performance and disconfirmation on beliefs elements of cognitive structures. Adv Consumers Res 1979; 6: 179 189.

[19] Woodruff RB, Cadotte ER. Jenkins RL. Modelling consumer satisfaction processes using expcrienced based norms. J Marketing Res 1983; 20: 296-304.

[20] Beroepskrachtenplanning 1991 (Manpowerplanning 1991). Rijswijk: Netherlands Ministry of Welfare, Public Health and Culture, 1991.

[21] Cook DT, Campbell DT. Quasi-experimentation: design and analysis issues for field settings. Chicago: Rand McNally Publishing Company, 1979.

[22] Rubin HR, Ware JE Jr, Nelson EC. Meterko M. The Patient Judgements of Hospital Quality (PJHQ) questionnaire. Med Care 1990; 28 (Suppl): S17-S18.

[23] Goldstein H, Wood R. Five decades of item response modelling. Br J Math Stat Psychol 1989; 42: 139-167. 
[24] Prosser R, Rasbash J, Goldstein H. ML3: software for three-level analysis. London: University of London, Institute of Education, 1991.

[25] Woodhouse G. Multilevel item response models. In: Prosser R, Rasbash J, Goldstein H editors. Data analysis with ML3. London: University of London, Institute of Education, 1991.

[26] McCullagh P, Nelder JA. General linear models, 2nd ed. London: Chapman and Hall, 1989.

[27] Draper NR, Smith H. Applied regression analysis, 2nd ed. New York: John Wiley \& Sons, 1981.

[28] Yperen EM van and Kerssens JJ. Kwaliteit van diëtetische zorg: het oordeel van de cliënt (The quality of dietetic care: client's evaluations). Neder Tijdschr Diëtisten 1992; 47: 198-204.

[29] Strasser SL, Davies RM. Measuring patient satisfaction for improved patient services. Ann Arbor, MI: Health Administration Press, 1991.

[30] Cleary PD, McNeil BJ. Patient satisfaction as an indicator of quality care. Inquiry $1988 ; 25 ; 25-36$.

[31] Rubin HR. Can patients evaluate the quality of hospital care? Med Care Rev 1990; 47: 267-326.

[32] Ley P, Kinsey J, Atherton A. Increasing patients' satisfaction with communication. Br J Soc Clin Psychol 1976; 15: 403-413.

[33] Hinshaw AS, Gerber RM, Atwood JR, Allen JR. The use of predictive modelling to test nursing practice outcomes. Nurs Res 1983; 32: 35-12.

[34] Kane RL, Klein SJ, Bernstein L, Rothenberg R, Wales J. Hospice role in alleviating the emotional stress of terminal patients and their families. Med Care 1985; 23 : 189-197.

[35] Carlberg A, Tibblin G. Patient satisfaction in primary health care: a comparative study of two modes of treatment for hypertension. Fam Pract 1992; 9: 304-310.
[36] Carlberg A, Patient satisfaction and design of treatment. Scand J Prim Health Care 1993; 11: 105-110.

[37] Vuori H. Patient satisfaction - does it matter? Qual Assurance Health Care 1991; 3: 183-189.

[38] Locker D, Dunt D. Theoretical and methodological issues in sociological studies of consumer satisfaction with medical care. Soc Sci Med 1978; 12: 283-292.

[39] Ware JE jr, Snyder MK, Wright WR, Davies AR. Defining and measuring patient satisfaction with medical care. Eval Progr Plan 1983; 6: 1-15.

[40] Wilkin D, Hallam L, Dogget MA. Measures of need and outcome for primary health care. Oxford: Oxford University Press, 1992.

[41] Aharoney L, Strasser S. Patient satisfaction: what we know about and what we still need to explore. Med Care Rev 1993; 50: 49-79.

[42] Zastowny TR, Roghmann KJ, Hengst A. Satisfaction with medical care: replications and theoretical reevaluation. Med Care 1983; 21: 294-322.

[43] Linder-Pelz S. Toward a theory of patient satisfaction. Soc Sci Med 1982; 16: 577-582.

[44] Linder-Pelz S. Social psychological determinants of patient satisfaction: a test of five hypotheses. Soc Sci Med 1982; 16: 583-589.

[45] Fishbein M, Ajzen I. Belief, attitude, intention and behavior: an introduction to theory and research. Reading, MA: Addison-Wesley, 1975.

[46] Fitzpatrick R, Hopkins A. Problems in the conceptual framework of patient satisfaction research: an empirical exploration. Soc Health Illness 1983; 5: 297-311.

[47] Strasser S, Aharoney L, Greenberger D. The patient satisfaction process: moving toward a comprehensive model. Med Care Rev 1993; 50: 219-248. 